\title{
Varicella-Associated Purpura Fulminans: Chicken Pox Is Not Always Benign
}

\author{
A. Abdulmalik W. Al-Ateeqi M. Al-Khawari S. Al-Osaimi \\ Department of Paediatrics, Al-Amiri Hospital, Safat, Kuwait
}

Key Words

Chicken pox $\cdot$ Purpura fulminans

\begin{abstract}
Objective: To report a 6-year-old boy with post-chicken pox purpura fulminans (PF). Clinical Presentation and Intervention: A 6-year-old boy presented with purpura of the legs that rapidly progressed to other parts of the limbs and the buttocks. The patient had had chicken pox 10 days prior to presentation. He was afebrile and the chicken pox lesions were dry. He received anti-coagulants, a large volume of fresh frozen plasma, immunoglobulin and steroids. The skin lesions regressed but both hands and parts of the lower limbs remained necrotic; the patient was transferred to an orthopaedic hospital for amputation and skin grafting. Conclusion: This case report shows that PF can occur as a post-infection syndrome after primary varicella. Early and aggressive treatment of post-chicken pox PF might reduce the mortality and morbidity associated with this condition.
\end{abstract}

Copyright $\odot 2006$ S. Karger AG, Basel

\section{Introduction}

Purpura fulminans (PF) is an acute, often lethal syndrome of disseminated intravascular coagulation with rapidly progressive haemorrhagic necrosis of the skin due to dermal vascular thrombosis $[1,2]$. The pathogenesis of
$\mathrm{PF}$ is not known but may involve acute transient decrease in protein C (PC), protein S (PS) or anti-thrombin III [3, 5]. Varicella-associated PF is a rare syndrome with substantial morbidity and mortality [6]. Onset is often sudden, usually 7-10 days after the onset of common chickenpox [2]. The lesions are characterized by ecchymoses that grow in size and number. Typically, lesions are seen mostly on the lower limbs, although the trunk and upper extremities can be involved [2, 4]. Clinically, skin lesions are characterized by progression from ecchymotic areas to circumscribed lesions of purple-black skin containing haemorrhagic bullae, eventually culminating in gangrene [1].

PF is usually seen in three clinical settings: in the newborn period as a manifestation of homozygous PC deficiency (or, rarely, PS deficiency); in individuals with acute, severe viral or bacterial infection, and as a rare post-infection syndrome, for example following varicella [1].

In this report we describe severe PF in a 6-year-old boy 10 days after a varicella infection that ended with skin necrosis which needed grafting and amputation of both hands.

\section{Case Report}

A previously healthy 6-year-old boy presented with purpura of the legs. These lesions were rapidly progressive and involved both hands, forearms, the right foot and parts of his thighs and buttocks.

\section{KARGER}

Fax +4161306 1234 E-Mail karger@karger.ch www.karger.com 


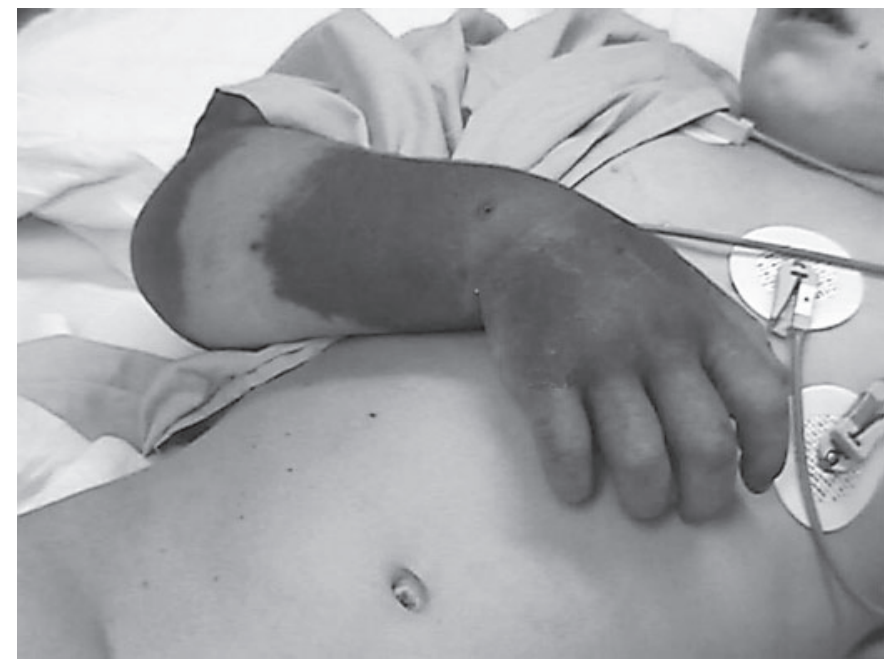

Fig. 1. Extensive purpura of the right hand and forearm.

There was a history of chicken pox 10 days prior to presentation. There was no history of fever, vomiting, headache, abdominal pain, joint pain or bleeding tendency. The patient was the first-born offspring of consanguineous parents. He had two healthy sisters who had had chicken pox. There was no family history of blood diseases or thrombotic disorders. On physical examination he was conscious, not toxic or ill-looking but depressed and screaming with pain. He was afebrile, respiratory rate was $25 / \mathrm{min}$, pulse rate 120 / min, blood pressure $150 / 70 \mathrm{~mm} \mathrm{Hg}$. He had extensive purpura on both hands up to the mid-forearms and the right elbow (fig.1). Both hands were cold and swollen. There was dry gangrene involving all fingers and extending to the palms, and purpuric lesions on the right foot, thighs and buttocks (fig. 2). The toes of his right foot were also gangrenous, as were multiple skin sites on the lower limbs. The chicken pox lesions were dry. Other systems were normal.

Blood investigations revealed a haemoglobin level of $4.9 \mathrm{~g} / \mathrm{l}$, leucocytosis of $14.4 \times 10^{9} / 1$, platelets $732 \times 10^{9} / 1$; renal and liver functions were normal. Coagulations profile: PT 16 (control 10), INR 1.6, APTT 40 (control 31), fibrinogen 1.48 g/l,D-Dimer $1,000 \mathrm{ng} / \mathrm{ml}$. Factor VIII-C 235\%, prothrombin $112 \%$, PC activity $49 \%$, PS activity $13 \%$, anti-thrombin activity $48 \%$, lupus anti-coagulant not detected. Anti-nuclear antibodies, anti-neutrophil cytoplasmic antibodies, tissue anti-mitochondrial antibodies, gastric parietal cell, liver kidney microsomal, antismooth muscle antibodies, glomerular basement membrane antibodies and reticulin antibodies were negative, anti-cardiolipin antibody IgG was 17.9 (normal <15) and IgM 30.1 (normal <10), anti-B2 glycoprotein I (IgG) was 18 (normal <15), IgM 33 and IgA was negative, C3 and C4 were normal, ASO titre was $200 \mathrm{IU} / \mathrm{ml}$. Urine, blood and swab cultures from fluid-filled bullae showed no growth. IgM for cytomegalovirus was negative. He was given a blood transfusion for severe anaemia and fresh frozen plasma $40 \mathrm{ml} / \mathrm{kg} /$ day for 1 week. He received intravenous immunoglobulin $1 \mathrm{~g} / \mathrm{kg}$ and intravenous methyl-prednisolone $30 \mathrm{mg} / \mathrm{kg} /$ day for 4 days, and was then switched to oral prednisolone $2 \mathrm{mg} / \mathrm{kg} / \mathrm{day}$. He was started on intravenous heparin infusion to maintain activated partial thromboplastin time at 55-85 s. After 2 weeks he was switched to oral warfarin to maintain

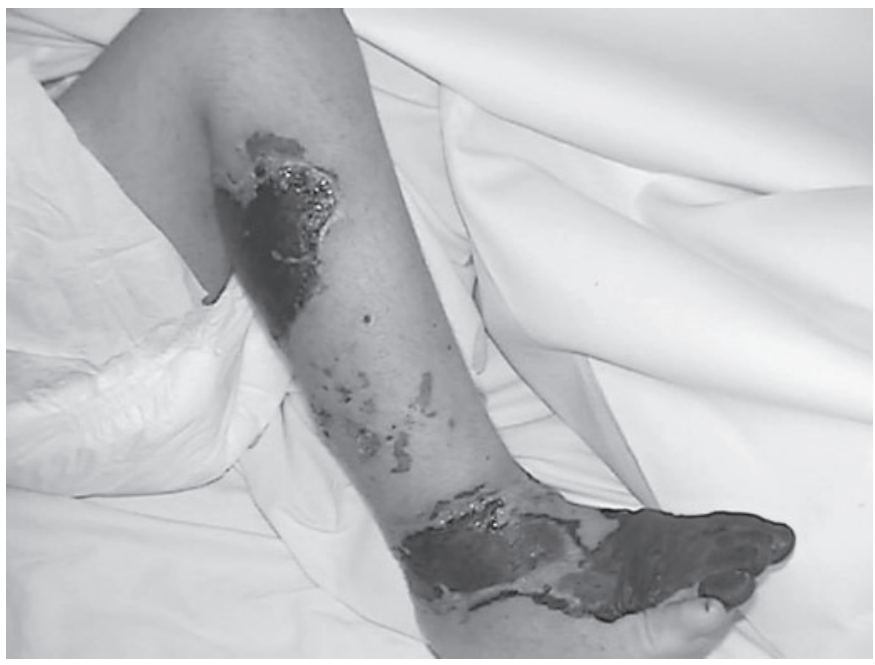

Fig. 2. Extensive purpura of the right foot and leg.

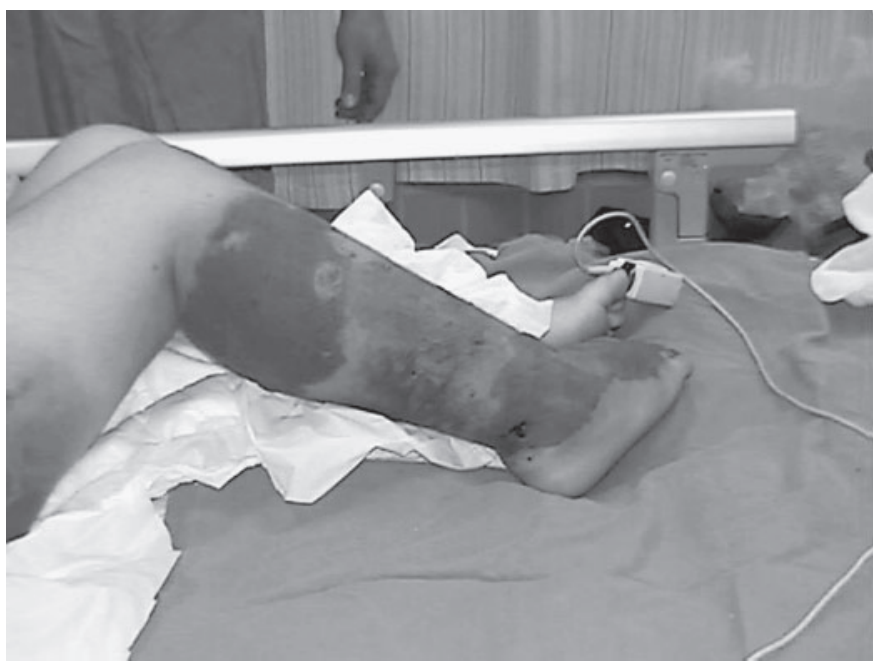

Fig. 3. Areas of skin necrosis with regression of skin lesions after treatment.

an international normalized ratio of $2-3$. After starting anti-coagulant therapy the skin lesions regressed; however, both hands and parts of the lower limbs remained necrotic (fig. 3). He was transferred to an orthopaedic hospital for amputation and skin grafting.

\section{Discussion}

Varicella is a common infectious disease, usually benign and self-limiting. Thrombotic PF complicating chicken pox is rare. Overall physical condition in post- 
infection PF is rarely altered and fever is uncommon [4]. The pathogenesis of post-chicken pox PF may involve acute transient deficiencies of PC, PS or anti-thrombin III $[1,4,5]$. Activated PC degrades activated coagulation factors VIIIa and $\mathrm{Va}$, attenuating their procoagulant activation of factors $\mathrm{X}$ and prothrombin. PS is a cofactor to activated PC [2]. Transient deficiencies of PS and PC, which returned to normal after 3 months, were present in our patient. Acquired PS and PC deficiency could be a consequence of disseminated intravascular coagulation or result from the presence of a specific antibody against the protein $[4,8,9]$. Patients with severe PF or disseminated intravascular coagulation associated with varicella usually have very low or undetectable PS concentrations. While children with uncomplicated varicella have mild free-PS deficiency [8], our patient had a very low PS level of $13 \%$, which could explain the severity of the clinical manifestation.

$\mathrm{PF}$ is often fatal and survivors may have considerable morbidity related to loss of digits, limbs, or areas of the skin - all of which was the case in our patient. Aggressive management is indicated for better prognosis. Great variability in the choice of treatment administered has been reported $[6,10]$. Recognition that the disorder is predominantly a thrombotic process resulting from a deficiency of anti-thrombotic factors suggested that prompt heparinization, even in the presence of severely deranged coagulation, is the preferred treatment [10]. This should be combined with aggressive blood product replacement using cryoprecipitate, concentrates of PC and anti-thrombin to replace factors consumed [6]. Anti-coagulation should be continued until the free-PS level returns to normal [6]. Plasma exchange permits the infusion of relatively large volumes of plasma while reducing the titre of the PS auto-antibody [6]. In our patient, anti-coagulants and large volumes of fresh frozen plasma were used to replace the low PS and PC levels. Immunoglobulin and steroids were also used as they may play a role in reducing anti-PS antibody levels.

The varicella vaccine has proven to be extremely effective and safe. In controlled trials, the varicella vaccine was found to be about $85 \%$ effective for preventing all cases of chicken pox, and almost 100\% effective in preventing severe cases [10]. Routine immunization of all susceptible children and adolescents without a contraindication is recommended. A reliable history of varicella should be sought at every childhood visit and children $\geq 1$ year as well as adults without a history of the disease should be immunized. The use of varicella vaccine in susceptible children after exposure to varicella is recommended and may be effective in preventing or modifying varicella when given to household contacts within 3 days of the appearance of the rash in the index case [10].

\section{Conclusion}

Our case shows that PF can occur as a post-infectious syndrome after primary varicella. Early and aggressive treatment of post-chicken pox PF might reduce the very significant morbidity and mortality associated with this condition.

\section{Acknowledgement}

We would like to thank Dr. Osama AlBaqsemi for his valuable contribution in the management of our patient.

\section{References}

-1 Gerson WT, Dickerman JD, Bovill EG, Golden $\mathrm{E}$ : Severe acquired protein $\mathrm{C}$ deficiency in purpura fulminans associated with disseminated intravascular coagulation: treatment with protein C concentrate. Pediatrics 1993;91: 418-422.

$\checkmark 2$ Woods CR, Johnson CA: Varicella purpura fulminans associated with heterozygosity for factor V Leiden and transient protein $\mathrm{S}$ deficiency. Pediatrics 1998;102:1208-1210.

-3 Nguyen P, Reynaud J, Pouzol P, Munzer M, Richard O, Francois P: Varicella and thrombotic complications associated with transient protein $\mathrm{C}$ and protein $\mathrm{S}$ deficiencies in children. Eur J Pediatr 1994;153:646-649.
Kay SK, Francois P, Pollack B, Moutet F, Cussac E, Bost M: Localized thrombotic purpura: a rare complication of chickenpox. J Pediatr 1997; 130:655-657.

$>5$ Sheridan RL, Briggs SE, Remensnyder JP, Tompkins RG: Management strategy in purpura fulminans with multiple organ failure in children. Burns 1996;22:53-56.

-6 Busuttil DP, Hay CR, Lewis MA, Wynn RF Aggressive multiple modality therapy for varicella-associated purpura fulminans. Br J Haematol 2000; 110:1012-1013.
$>7$ Levin M, Eley BS, Louis J, Cohen H, Young L Heyderman RS: Postinfectious purpura fulminans caused by an autoantibody directed against protein S. J Pediatr 1995; 127:355363.

8 Kurugol Z, Vardar F, Ozkinay F, Kavakli K Ozkinay $\mathrm{C}$ : Lupus anticoagulant and protein $\mathrm{S}$ deficiency in otherwise healthy children with acute varicella infection. Acta Paediatr 2000; 89:1186-1189

9 Manco-Johnson MJ, Nuss R, Key N: Lupus anticoagulant and protein $\mathrm{S}$ deficiency in children with postvaricella purpura fulminans or thrombosis. J Pediatr 1996;128:319-323.

10 American Academy of Pediatrics, Committee on Infectious Diseases: Varicella vaccine update. Pediatrics 2000;105:136-141. 